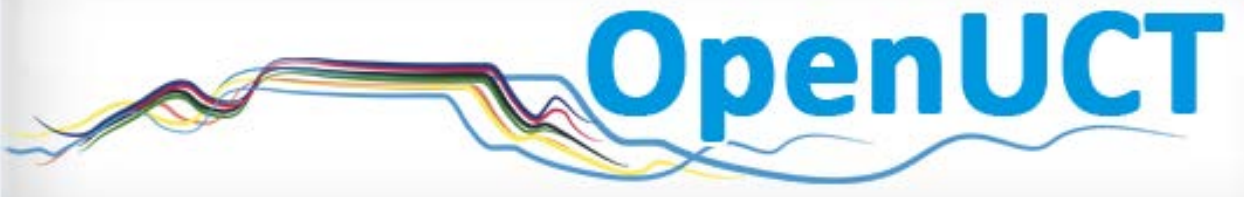

This is the post-print of Archer, A. \& Stent, S. 2011. Red socks and purple rain: the political uses of colour in late apartheid South Africa. Visual Communication. 10(2): 115-128. DOI 10.1177/1470357211398437.

It is made available according to the terms of agreement between the author and the journal, and in accordance with UCT's open access policy available: http://www.openuct.uct.ac.za/sites/default/files/UCTOpenAccessPolicy.pdf, for the purposes of research, teaching and private study. 


\title{
Red socks and purple rain: the political uses of colour in late apartheid South Africa
}

Arlene Archer and Stacey Stent

University of Cape Town, South Africa

\begin{abstract}
This article explores the extent to which colour functions as an independent mode in a particular context and explores the culturally produced regularities in the uses of colour in this context. Drawing on a Hallidayan metafunctional view of text, we look at how colour instantiated systems of knowledge and belief (ideational function) and social relations and identities (interpersonal function) in South Africa during the last decade of the apartheid government. In this type of repressive socio-political context, colour was a less policed mode, and thus had different affordances to images and the verbal modes. We argue that colour can function as an independent mode under certain conditions, such as stringent press restrictions, where the use of colour in a range of media (clothing, flags, posters) can play a crucial role in communicating.
\end{abstract}

\section{Key words}

colour $\bullet$ metafunctional view of text $\bullet$ mode $\bullet$ social semiotics

\section{INTRODUCTION}

This article explores Kress and Van Leeuwen's (2002, 2006) notion of colour as a semiotic mode and the extent to which colour can operate as a mode on its own, or can only function in complexes of modes. By mode, we mean the culturally-shaped material available for representation that is used in recognizably stable ways. We explore the 'mode-like' status of colour by looking at the way colour functioned in a particular context, namely the South African resistance movement against the apartheid regime in the 1980s and 1990s. According to Kress and Van Leeuwen (2002: 350), 'language, image and music have been conceived of (and have in various "purist” practices often operated) as relatively independent semiotic modes.' They argue that colour can combine freely with many other modes, and they raise a question about the extent to which it can exist on its own or whether it 'can survive only in a multimodal environment' (p. 351). We contend that should the social environment require it, colour can function largely as an independent mode without having to depend on accompanying verbal text or images for meaning-making. However, colour as mode does need to be realized in a particular medium or site of display, and we explore the affordances of the media utilized during the South African resistance movement, including clothes, flags and political posters. We also look at changes in meanings of colour over time and what these signify, including the shifts from red to green and yellow, and eventually to monochrome.

\section{SOCIAL SEMIOTIC PERSPECTIVE: A ‘GRAMMAR’ OF COLOUR}

This kind of investigation has a long history in semiotics, in the work of people such as Eco (1979) and Barthes (1977) where there has been an attempt to look at whether and how a range of signs can function as a 'language'. We are interested in the semiotic possibilities of colour along the lines of these semioticians, but within a particular context. This investigation into how modal resources such as colour are used in specific historical, cultural and institutional contexts constitutes part of a social semiotic research agenda (Van Leeuwen, 2005: 3).

Colour is often attributed to cultures or nations in fairly simplistic and stereotypical ways, such as 'Latinos like warm colours, Scandinavians prefer blues, Africans have an affinity for bright colours' (Hoffman, 2004). However, this is not what Kress and Van Leeuwen (2002: 343) mean when they talk about 'culturally produced regularities'. They note the contrasting 
meanings of colour in different social groups such as white being a colour of mourning in China and brides in certain regions of Portugal wearing black. This use of black and white communicates a particular view of death and marriage in these communities. Kress and Van Leeuwen point out that there is no large group sustaining the meanings of colour across all of society in a universal way and, as a result, question whether colour can operate as a 'grammar'. Grammar can either be seen as a set of rules, or it can be seen as something that creates meaning within a particular context. In the latter view of grammar, meaning is not seen as a product. Rather, any meaning-making or textual representation is a social act which takes place within a particular institution, with a particular history, culture, set of values and practices. This is a point well established in the work of Halliday and other social semioticians. According to Halliday (1978: 2), 'social semiotic' means 'interpreting language within a sociocultural context, in which the culture itself is interpreted in semiotic terms'. Human semiosis is an inherently social phenomenon, where meaning comes into being between participants.

In looking at colour, we draw on this Hallidayan (1985) view of grammar that includes three kinds of semiotic work, namely the ideational, interpersonal and textual metafunctions. The ideational metafunction represents objects and their relations in a world outside the representation system. Colour is interesting in this regard as it has 'immediate perceptual and cognitive significance in human experience' (Varela et al., 1991, in Puhalla, 2008: 199). An enlightening example to illustrate the ideational metafunction of colour is that of rural herdsmen in Namibia in the 1880s who had hundreds of colour words for livestock, but no words for blue and green (Kay and Berlin, 1969). The contextual circumstances of these herdsmen dictated that they develop a complex colour language for their specific needs. This indicates how a specific way of using colour in meaning-making can develop according to the specific needs and environment of a community.

The interpersonal metafunction refers to the role that language or a semiotic system plays in creating interactions between producers of texts and audiences. Kress and Van Leeuwen (2002: 348) give some examples of how colour can convey interpersonal meaning, such as using colour to impress or intimidate through 'power dressing' or warn against danger. In addition, we argue that colour used for social or political ends can facilitate political awakening into actions. Here, colour is used to act on people. It is also used by people to present their ideas and the values they stand for.

Finally, the textual metafunction refers to the capacity to form coherent complexes of signs or texts. Textual meaning enables the producers and users of text to make and recognize patterns and relations so that the various elements in the constituting discourses relate to each other. Kress and Van Leeuwen (2006) talk about repetition of a single colour and 'colourcoordination' being used to create textual cohesion. Colour can function as a system of meaning-making across a society, and it is on the textual level that it can do so. In this way, colour offers the semiotic possibility of 'association' with other colours and their meanings in a particular society. The Hallidayan multi-functional view of semiosis is particularly useful when looking at colour as it provides a way of investigating the simultaneous constitution of systems of knowledge and belief, and social relations and identities.

If colour has the full affordances of a mode, then it can operate across all three metafunctions. However, as Kress and Van Leeuwen (2006) caution, colour does not always fulfil all three of these functions equally in any one context. Kress and Van Leeuwen (2002) address these questions by providing a 'negative definition' of what constitutes a mode - we know something is a mode or that it has a grammar when we recognize that the conventions of the grammar have been contravened. This leaves us with the task, then, to

discover the regularities of the resource of colour as they exist for specific groups ... to understand how specific groups' interests in colour shape the signs of colour; and to 
understand what general principles of semiosis and of the specific semiosis of colour emerge from this that might provide a principled understanding of all uses of colour in all social-cultural domains. (p. 346)

It was this challenge that led us to 'try out' Kress and Van Leeuwen's theory in a specific domain, namely the changing South African political contexts. Our main interest lies in showing how colour can be significant socially as well as theoretically, and to look at the role of colour in meaning-making within the boundaries of extreme social and political environments.

\section{AFFORDANCES OF COLOUR AS MODE}

When compared to written and spoken language, the importance or impact of colour as mode may seem limited. There are, however, practices of colour coding that have different affordances or semiotic possibilities to the spoken and written modes in certain contexts. Certain kinds of knowledges, experiences and identities are enabled by different media and modes. For instance, the affordances of the visual are different from those of the verbal. The semiotic logic of the visual includes more display, spatial arrangement, co-presence of representational elements than the verbal, whereas the semiotic logic of the verbal includes more linearity and sequencing in time (Kress, 2000), although these are not clearcut divisions (Archer, 2006). In terms of the textual metafunction, the affordances of colour also include display and spatial arrangement, depending on the site of display. Perhaps the strongest affordance of colour in metafunctional terms, is the 'interpersonal'. Colour, with its capacity for both individual and conventionalized meanings, is able to express both personal and communal sentiments, and strong group affiliations. For instance, the Nationalist Party, who ruled apartheid South Africa between 1948 and 1994, was strongly associated with the colours orange, white and blue. These were the colours of the first flag of the Republic of South Africa and subsequently became the colours identified with apartheid. The media then framed many of its racist messages within these colours and any identification with orange, white and blue subsequently became an anathema in black communities. Colour thus becomes invested with strong emotional significance in this context. This is a common 'affordance' of colour as it is often used to convey emotional states of being, such as 'feeling blue' or red signifying love.

Towards the end of the apartheid era, colour also fulfilled a distinctly ideational function, as an 'information-carrier'. From the 1950s, it was illegal to promote the aims of a banned organization - in posters, in speeches, or by marching through the streets. South Africa, on the verge of huge political change, required mass action and fast communication among a nation of people who spoke a variety of languages and whose literacy levels were low. As mentioned earlier, news was severely censored and resistance movements had to find creative ways of distributing information. In a repressive state environment such as this, colour was, for a time, a less policed mode than words or images. It did, however, become more policed over time. According to Bleicher (2005: xv), colour as mode could be compared to music as they both 'have rhythm and harmony and are used to add emphasis and feeling. They can play directly on our senses and emotions and bypass our conscious minds, or they can be used for purely intellectual pursuits', thus operating across all three metafunctions.

Another feature of colour is that it is able to communicate through a variety of 'alternative' media or sites of display, such as clothing, which enables different kinds of messages to be communicated in different contexts from images or the verbal mode. Joe Slovo, General Secretary of the Communist Party of South Africa, on returning home for the first time 
in 1990 after 25 years in exile, sent a message to his supporters anticipating his arrival. 'Wear red socks', he said and thousands did. No written explanations, images or verbal slogans were needed. When people put on their red socks for Slovo, they were acknowledging their own history of concurring with the sentiments, politics and strategies of the South African Communist Party, and joining these thoughts with the quirky humour of the leadership. The choice of media, namely socks, was deliberate because socks are not immediately and overtly discernible and can be shown or hidden at will. Political colours were also conveyed in other items of clothing, such as T-shirts, caps, scarves, and other adornments, such as umbrellas. Socks were not necessarily 'meaningful' media, in the sense of communicating a political message, before Slovo invested them with meaning. Perhaps different items of clothing revealed different degrees of investment and risk-taking behaviour in this context. A cap, for instance, is more readily disposable than a T-shirt, which represents stronger commitment as a media of representation. What is interesting about clothes as media is that they can be used more or less overtly to convey a message. Yet, clothes embody one's political standpoint to a different degree than, say, a poster or placard. The body becomes text and the carrier of the message in a different way.

The wearing of colour to signify group affiliation could be compared to the colour branding of sports teams and the type of support this generates, such as wearing a red scarf at a football game to signify support of Arsenal. The principle is perhaps similar to the political context we are sketching, where colour is used to demarcate social groups (Scollon and Scollon, 2003). Wearing a particular colour in these cases signifies belonging to a community, whilst simultaneously signifying resistance or opposition to another community. However, the difference in the use of colour in the South African struggle situation is the complexity of the messages that relied only on colour, and the unifying of so many diverse groups under those colours. The discourse of opposition to the state signified by particular colours unified an array of people from a range of political perspectives.

One of the key forms of resistance was graphic - political posters that recorded and engaged with the struggle for a liberated South Africa. From 1975 to 2000, large numbers of people produced a massive amount of posters, somewhere around 4000 (Seidman, 2007: 11). In looking at how the colours red, black, green and gold were employed in the South African struggle, we look at three popular political posters that are representative of the many posters in the public eye between the early 1980s and 1990s.

\section{A STORY ABOUT RED, BLACK, GREEN AND GOLD}

The most eminent example of the role that colour can play in aligning political thought is the colour red depicting left thinking. Red was used with huge political effect during the French revolution, where it symbolized the blood of the angry workers. The colour, devoid of written text or image, has continued to convey socialist and communist sentiments in both global and local discourses. Red is commonly used in flags, but it can mean an array of things depending on the symbols of nationhood: 'war, blood, bravery, authority, fire, unity, revolution, soil, sacrifice, faith, sun, freedom ... independence, law and authority, brotherhood and equality, nation, charity, vitality and friendliness, warmth' (Gage, 2006: 153). Flags present colour symbolism at its most public, and the colours are always highly charged national symbols.

The United Democratic Front (UDF) in South Africa, launched in 1982 and patently sympathetic with leftist politics, stamped its colours, black, yellow and red, on the psyche of the nation: black for the people, yellow or 'gold' for the wealth, red to signify alignment with leftist politics (see Figure 1). The UDF was an umbrella organization with dozens of affiliates stemming from diverse interest groups, such as church goers, workers, students, women and youth. It was aligned with the ANC and other banned organizations, but its formation signified 
a break with sectorial politics and a united focus by these different organizations. After the UDF was formed, the Defiance Campaign intensified. In the Defiance Campaign, different organizations worked together to defy the laws of the land through structured, broad-based and organized opposition. This defying of oppressive laws took different forms - for instance, people congregated on beaches designated for 'whites only', boycotted the use of certain products in sympathy with workers' demands, attended protest marches and public meetings, and produced a range of 'underground' publications.

Figure 1 is typical of the posters produced at this time, comprising a limited palette of flat simple hues, a linocut feel and overt symbolism. It is an advertisement for a play, entitled Time to Act. It depicts the UDF as a permanent bonding substance, strong glue, which binds the people together through a shared ideology. This is represented by the intense and bright (saturated) hues of yellow and red which indicate the tributaries that connect the fragmented black map of South Africa. These colours are echoed in the UDF emblem and in the title of the poster. The high walls show how isolated South Africa is from the rest of the world, whilst the yellow of the opening horizon points to the utopian future. The colours in the image thus signify both resistance and communal affiliation. In terms of Halliday's textual metafunction, the use of the black, yellow and red colour scheme acts as a unifying element between this and other images of resistance at this time. Within these images, tints and shades of the hues were used, but the colour remained within the tricolour schema.

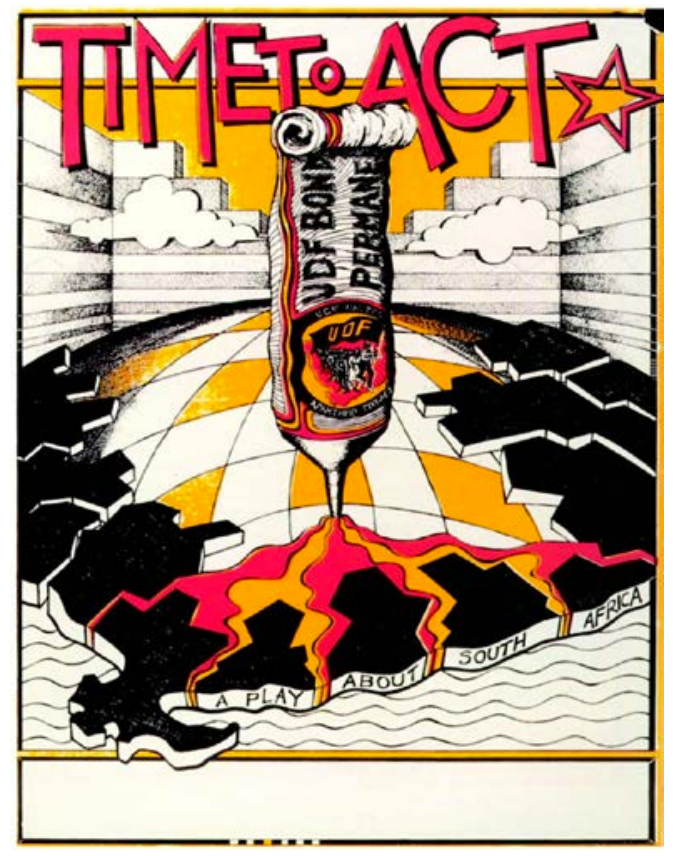

Figure 1 Poster printed at Community Arts Project in 1983 advertising a theatre performance by Action Workshop dealing with the South African liberation struggle. (Posterbook Collective, 1991: 173)

The colours of the African National Congress (ANC), which was established in 1912 and later became the government in exile, were (and still are) black, green and gold (see Figure 2). The colours represented aspirations for the majority of the country: black for the people, green for the land and gold for the wealth. These colours have become synonymous with a new African history and it is noteworthy that they have been adopted by at least three of South 
Africa’s neighbouring countries and adapted for their own use, namely Mozambique, Tanzania, Zimbabwe. Interestingly, for our purposes, following the banning of the ANC in 1960, the colours went 'underground'. People found by the regime to be in possession of items bearing these colours (no additional writing or image necessary) ran the risk of being beaten up, arrested or even killed.
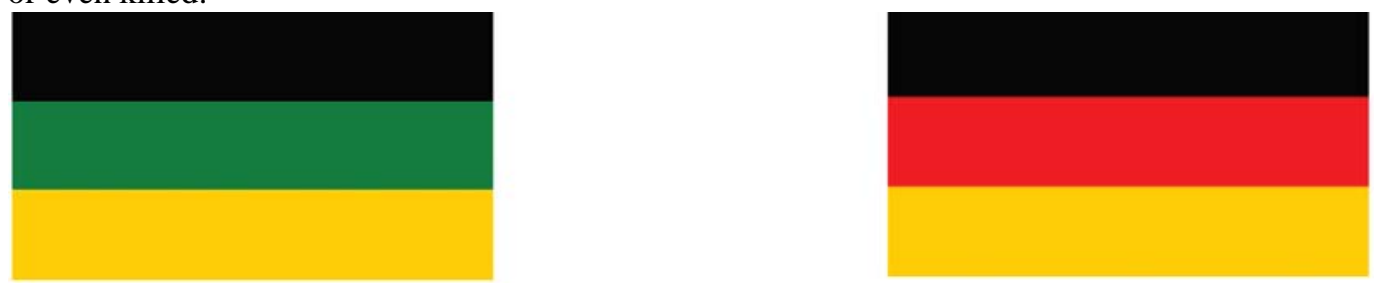

Figure 2 The black green and gold denoting the colours of the ANC established in 1925. The inclusion of a shield and spear, now the ANC flag, was adopted in 1985. The black, red and yellow of the United Democratic Front colours adopted in 1982 temporarily replaced black, green and gold as the colours of resistance until the unbanning of the ANC and other organizations in 1990.

While it may not have been possible for colours to communicate where and when a meeting was going to be held, colours alone could state not only opposition to apartheid, but also support for the armed struggle against it. The colours were in many cases used to give political clarity to written texts and images, but they were also used increasingly on their own. For instance, small indications of colours outside a building could signify a 'safe house' or a meeting venue.

History took its course, the ANC was unbanned and it spent from 1990 to 1994 preparing for the national election. Black, green and gold soon became re-established as the people's colours and the ANC took full advantage of this, flooding the media and swiftly rendering the UDF colours (black, red and yellow) as a thing of the past (see Figure 3).

The poster shown in Figure 3 represents Nelson Mandela after his release from prison. It communicates the strength of the ANC through the 'ideal' positioning (Kress and Van Leeuwen, 2006) of the emblem on the left, Mandela's raised fist and the word 'Mandela Released!' The poster functions to rally support for the ANC in the same way that Figure 1 rallied support for the United Democratic Front. It also signifies resistance to the state with the invocation to 'Free all political prisoners'. This poster represents a shift from the black, red and yellow of the UDF. The ANC colours dominate the visual mode and red remains for the written text. However, it is interesting to note how quickly the colour red disappeared from these posters and popular media altogether (see Figure 4).

The poster shown in Figure 4 was issued by the National Reception Committee set up in 1989 to welcome long-serving political prisoners. A prolific outpouring of posters, murals and flyers, all in the ANC colours of black green and gold, heralded the arrival of those who had served time with Mandela or were returning from exile. The poster depicts the ANC salute which was adopted in June 1949: 'The Congress salute is the right hand clenched with the thumb upraised. It represents the unity of the people in Africa' (ANC Handbook, 1958, in Seidman, 2007: 38). 


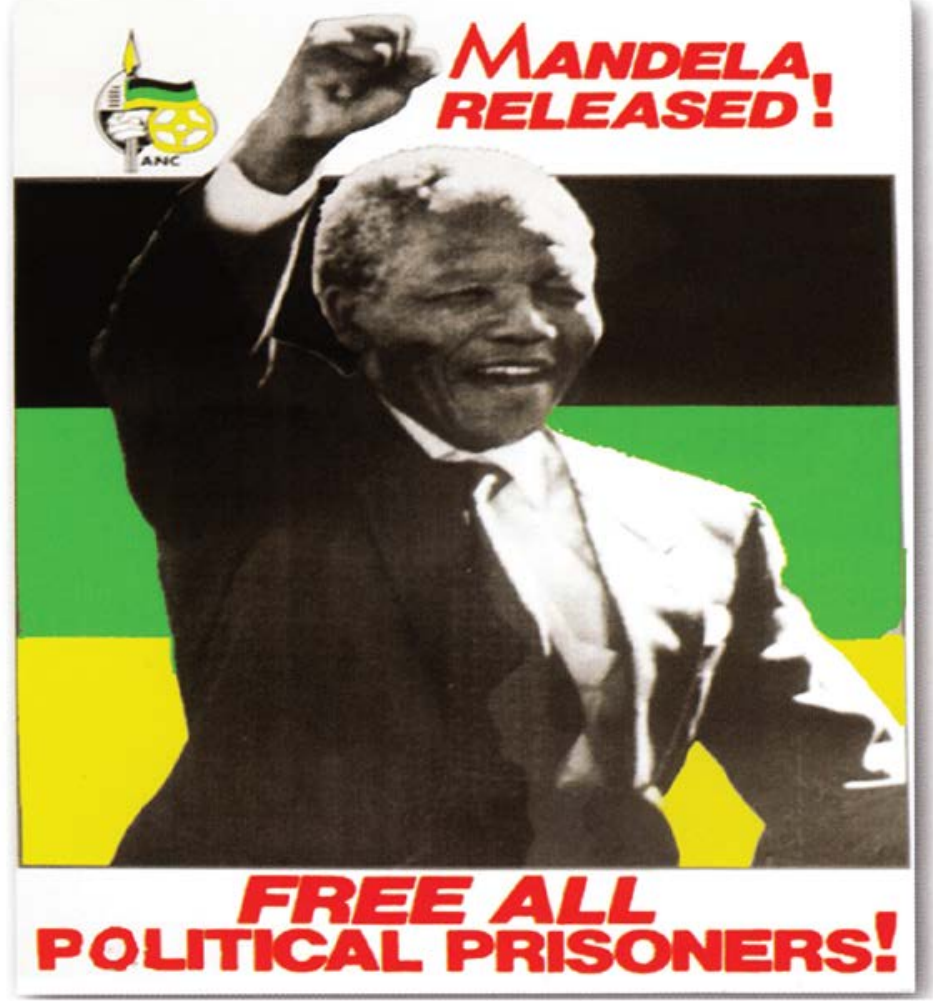

The raised fists evoke images of mass resistance, people's power and unified opposition to the state. The strong visual statement of these fists is echoed in the exclamation mark of the written slogan, 'Long live ANC!' Some would argue that the ANC, now in its 17th year of government, is not always seen as worker-friendly and has opted for a far more capitalist solution than originally anticipated. This may have been reflected in their colour coding from the start through the absence of red - and even the choice of 'gold' with its connotations of wealth.
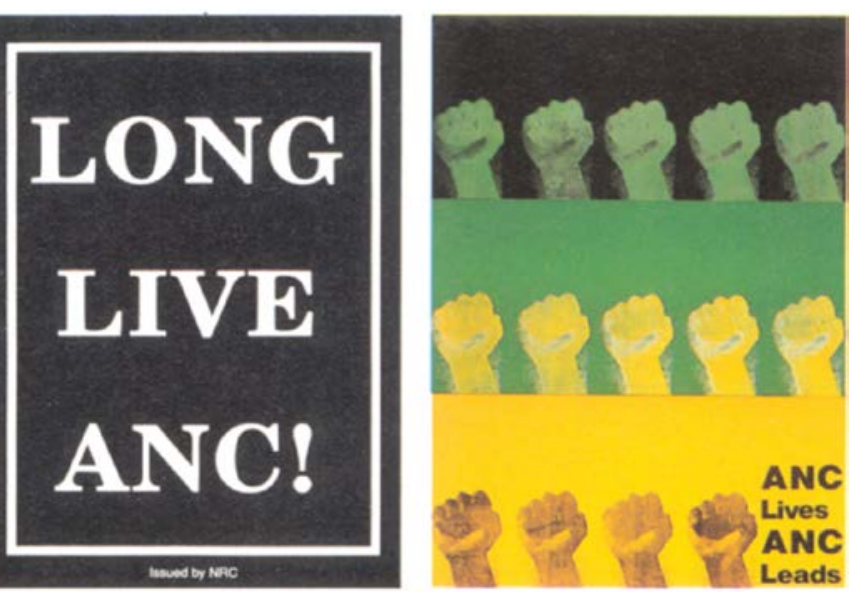
Figure 4 Poster produced in 1989 for the National Reception Committee by TOPS (The Other Press Service) in Johannesburg shortly before the unbanning of the ANC (Posterbook Collective, 1991: 22).

\section{THE SHIFT TO MONOCHROME: 'THE PURPLE SHALL GOVERN'}

It is our contention that colour as mode worked most effectively when social and political conditions were in crisis and at a point of urgency. The strong, flat and unmodulated colours that printers call 'spot' colours worked well as a mode of communication where communal identity and political affiliation needed to be established fast and messages needed to be conveyed with as much clarity as possible. However, when social conditions are less fraught and messages are conveyed with less urgency, colour coding reflects this different environment. It is notable that colours become muted, even monochrome, when messages are more benign. Playing with tonal relationships in visual communication speaks of time and luxury. A monochromatic scheme is the full range of a hue from its deepest shade to its lightest tint and if a hue is mixed with grey, a 'tone' is created (Bleicher, 2005: 55). In an atmosphere of political stability, posters informing the public of exhibitions, films or meetings do not have to jolt the viewer into action or have them reflect on their political affiliation. It is interesting to observe that posters about Dafur, the DRC or Rwanda circulating the world are often printed in muted colours or monochrome, but these are posters that are not being generated from within the country. They are more about the developed world informing itself about a far-away situation and therefore have an 'arty' coffee table book quality to them.

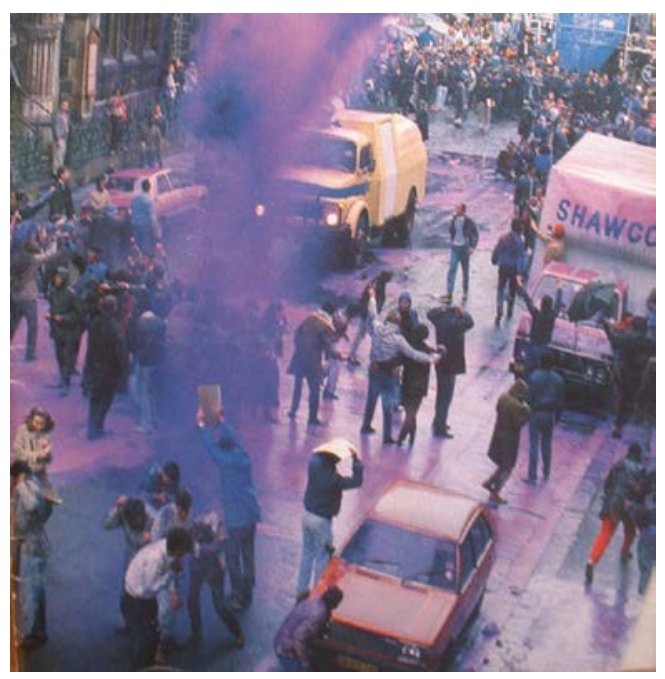

Figure 5 Police firing 'purple rain' on protesters, Cape Town 1989 (photographer unknown, from the cover of Die Suid Afrikaan, 1989, Tafelberg Publishers).

The key semiotic affordance of monochrome is the restraint involved in the lack of stark colour differentiation. Kress and Van Leeuwen (2006: 234) argue that a monochrome colour scheme has become a key signifier of the ideologies of postmodernism in which 'hybridity' is positively valued. Monochrome reflects and constructs our current social and political atmosphere of relative subtlety and 'greyness'. Much of our visual media, even of a political nature, is currently conveyed in monochrome. Top fashion houses, like Dolce \& Gabbana and Calvin Klein, display monotone wardrobes. Movie posters, which used to excel in the most blatant primary colours, now mirror the shift to monochrome. Advances in technology have enabled this shift to happen with convincing aesthetic standards. The colour palette of the internet and its applications have undoubtedly had an influence and many websites skilfully utilize the 
semiotics of colour. While six million colours may seem like a lot, this is in fact a small number compared to the infinite colours found on Rembrandt's palette. However, since web palettes are so visible and accessible to millions of people who would not formerly have given time to colour considerations, a general intoxication with modulated or 'flat' colour has been encouraged. In a way, the personal computer has 'democratized' colour, if, as Gage (2006: 31) argues, muted colours are considered more tasteful to those in a higher socioeconomic bracket, while 'bright saturated hues may be considered more common, popularist and egalitarian'.

Before ending, we want to note an ironic event that took place in Cape Town towards the end of 1989, during the height of the Defiance Campaign and shortly before the unbanning of the major South African political organizations. On 2 September, police turned a powerful water cannon on thousands of protesters attempting to march to parliament. The water contained a strong purple dye (see Figure 5), the intention being to mark all those who were protesting so they could face arrest at a later time, even if they managed to run away. Hundreds were arrested and for days it seemed a large part of the Cape Town population had become various shades of purple. This flew in the face of racial segregation laws and became a standing joke. People filled out 'purple' on the section of the arrest forms that demanded information about race and the defiance campaign slogan was changed temporarily to 'the purple shall govern'. Ironically, the event contributed successfully to the Defiance Campaign in that people with different skin colour looked more alike. 'Purple people' signified the ultimate embodiment of the mode of colour as a political statement, more than the media of clothes mentioned earlier. Unwittingly, this particular event also coincided with and marked the end of the era of colour being used as a mode with ideational urgency as we moved into a new monochrome phase.

\section{CONCLUSION}

We have attempted to explore the notion of colour as mode, namely the ability to construct textual and interpersonal relations through colour, as well as a more complex link between colour and ideational meaning, as used by South African organizations to mobilize masses of people. Colour need not only function as one mode among many, but can exist 'on its own' in a given time and place with broadly shared conventions in a community of practice. We have also shown that colour does not always have 'mode-like' status (Kress and Van Leeuwen, 2001: 25), but that it depends on the context and usage. Perhaps a more useful question is not whether colour is a mode, but when does colour function as a mode? It is our contention that one context in which colour operates most effectively as a semiotic force is that of excessive press censorship, and in an environment where many cannot read or write. Under these conditions, messages realized through alternative modes and media need to be delivered often and as quickly as possible. Chosen colours initially accompany particular written or visual messages and, with time, those signifiers become less reliant on other modes and media, to the point where a message can be imparted purely by colour, realized in a range of media or sites of display. Therefore, extreme political conditions that include press restrictions can utilize colour in this iconic sense to convey multifaceted messages. Here, colour as mode depends on 'sign makers acting within the needs and understanding of a particular community and its more or less conventionalized practices' (Bezemer and Kress, 2008: 172).

As Kress and Van Leeuwen (2006: 228) argue, social groups that share common purposes around uses of colour are often relatively small and specialized compared to groups who share speech or visual communication. In our explorations, we have come to see colour more as a 'dialect' than a universal language, as it is so dependent on context, as illustrated by the specificities of the South African situation. We have also shown how the link between colour as mode, and the particular media in which it is realized, are of interest, such as in items of clothing, where subtlety and the nuancing of overtly anti-state messages are necessary. Here, colour as a modal resource is able to be used in a particular site of display, namely the body, in 
a way that the visual and the written mode are not. It is thus clear that colour as signifier carries a 'set of affordances from which sign-makers and interpreters select according to their communication needs in a given context’ (Kress and Van Leeuwen, 2006: 232).

\section{ACKNOWLEDGEMENTS}

This research is based upon work supported by the National Research Foundation (NRF) in South Africa and the University Research Committee at the University of Cape Town. Any opinions, findings or recommendations expressed in this material are those of the authors and therefore the NRF does not accept any liability in regard thereto.

\section{REFERENCES}

Archer, A. (2006) 'A Multimodal Approach to Academic "Literacies": Problematizing the Visual/Verbal Divide’, Language and Education 20(6): 449-62.

Barthes, R. (1977) Image Music Text. London: Fontana Press.

Bezemer, J. and Kress, G. (2008) 'Writing in Multimodal Texts: A Social Semiotic Account of Designs for Learning', Written Communication 25(2): 166-95.

Bleicher, S. (2005) Contemporary Color Theory and Use. New York: Thomson Delmar Learning.

Eco, U. (1979) The Role of the Reader: Explorations in the Semiotics of Texts. Bloomington: Indiana University Press.

Gage, J. (2006) Colour in Art. London: Thames \& Hudson.

Halliday, M.A.K. (1978) Language as Social Semiotic: The Social Interpretation of Language and Meaning. London: Arnold.

Halliday, M.A.K. (1985) Spoken and Written Language. Melbourne: Deakin University Press.

Hoffmann, L. (2004) 'The Psychology of Colour: The Creative Artist'. URL (consulted May 2007): http://creativeartist.com/decArts/psycheColour.asp

Kay, P. and Berlin, B. (1969) Basic Color Terms: Their Universality and Evolution. Berkeley: University of California Press.

Kress, G. (2000) 'Multimodality', in B. Cope and M. Kalantzis (eds) Multiliteracies: Literacy Learning and the Design of Social Futures, pp. 182-202. London: Routledge.

Kress, G. and Van Leeuwen, T. (2001) Multimodal Discourse: The Modes and Media of Contemporary Communication. London: Arnold.

Kress, G. and Van Leeuwen, T. (2002) 'Colour as a Semiotic Mode: Notes for a Grammar of Colour', Visual Communication 1(3): 343-68.

Kress, G. and Van Leeuwen, T. (2006) Reading Images: The Grammar of Visual Design. London: Routledge.

Posterbook Collective (1991) Images of Defiance: South African Resistance Posters of the 1980s. Johannesburg: Ravan Press.

Pulhalla, D.M. (2008) 'Perceiving Hierarchy through Intrinsic Color Structure', Visual Communication 7(2): 199-228.

Scollon, R. and Scollon, S.W. (2003) Discourses in Place: Language in the Material World. London: Routledge.

Seidman, J. (2007) Red on Black: The Story of the South African Poster Movement. Johannesburg: STE Publishers/South African History Archive.

Van Leeuwen, T. (2005) Introducing Social Semiotics. London: Routledge. 


\section{BIOGRAPHICAL NOTES}

ARLENE ARCHER is Writing Centre Co-ordinator, Academic Development Programme, Centre for Higher Education Development at the University of Cape Town, South Africa. She teaches in Applied Language Studies, Higher Education Studies, Film and Media. She has published in journals such as Language and Education, English in Education, Social Dynamics, Teaching in Higher Education and the British Journal of Educational Technology.

Address: Academic Development Programme, Centre for Higher Education Development at the University of Cape Town, Hlanganani Building, University of Cape Town, Private Bag, Rondebosch 7700, South Africa. [email: arlene.archer@uct.ac.za]

STACEY STENT is the graphic designer and animator for the Centre for Educational Technology at the University of Cape Town, South Africa. She works in online and print media and gives workshops and lectures on design. During the apartheid years in South Africa, as well as being a satirical cartoonist, she worked with resistance groups producing posters, pamphlets and other visual media.

Address: Centre for Higher Education Development, Room 6.20, Hlanganani Building, University of Cape Town, Private Bag, Rondebosch, 7700, South Africa. [email: stacey.stent@uct.ac.za] 
Figure 1 Poster printed at

Community Arts Project in 1983 advertising a theatre performance by Action Workshop dealing with the

South African liberation struggle. (Posterbook

Collective, 1991: 173)

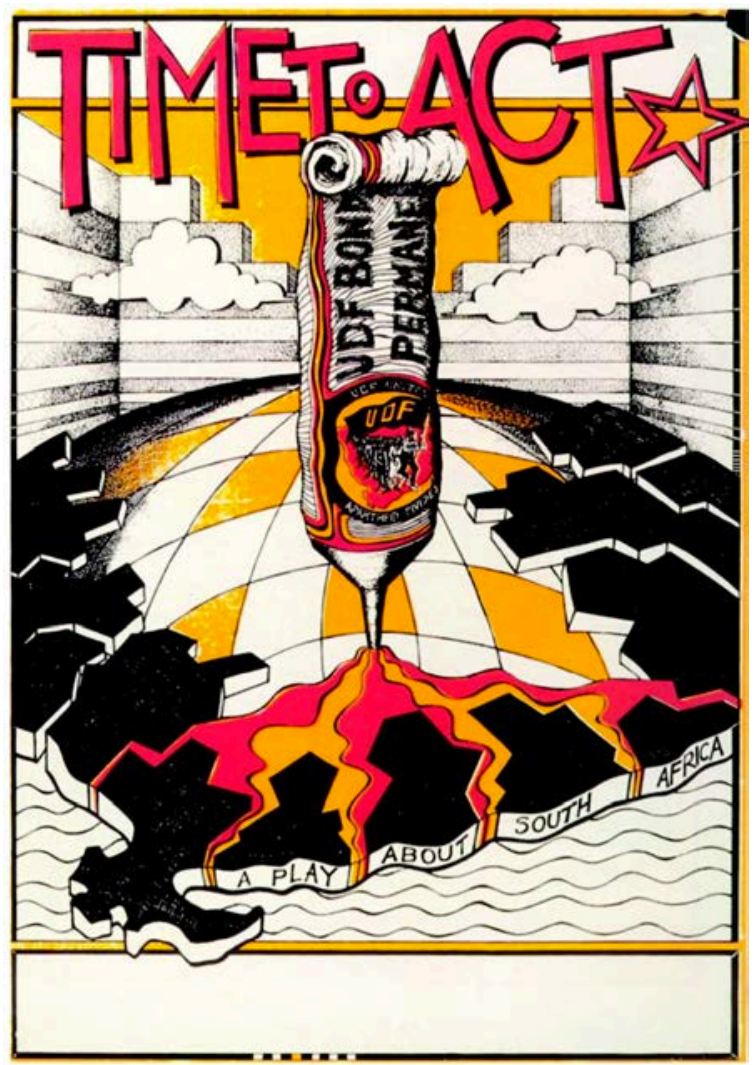


Figure 2 The black green and gold denoting the colours of the ANC established in 1925. The inclusion of a shield and spear, now the ANC

flag, was adopted in 1985

The black, red and yellow of the United Democratic Front colours adopted in 1982 temporarily replaced black, green and gold as the colours of resistance until the unbanning of the ANC and other organizations in 1990. 


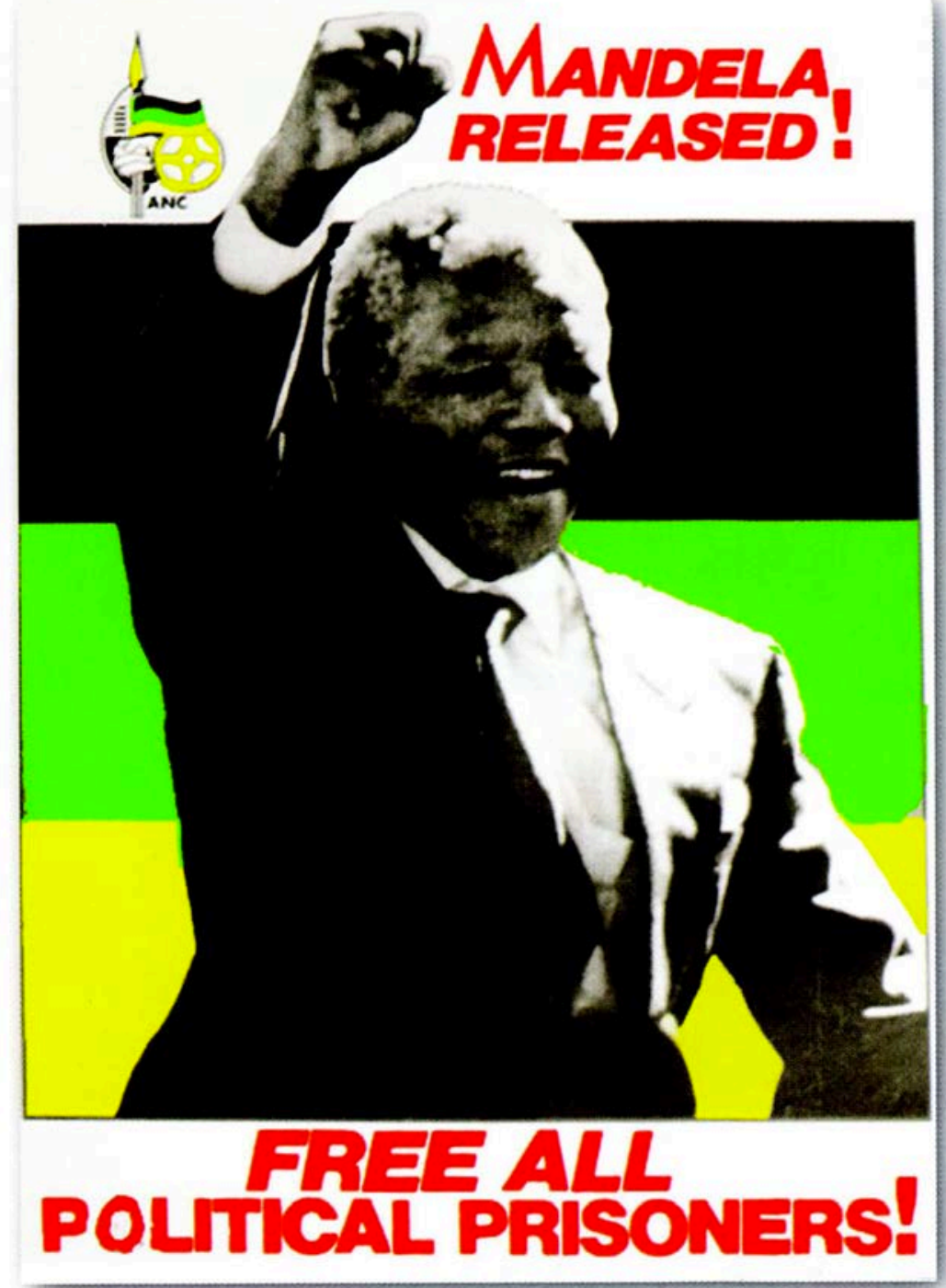

Figure 3 Photo taken on the day of Mandela's release (11 February 1990) and made into an ANC poster (Seidman, 2007). 
Figure 4 Poster produced in 1989 for the National Reception Committee by TOPS (The Other Press Service) in Johannesburg shortly before the unbanning of the ANC (Posterbook Collective, 1991: 22).
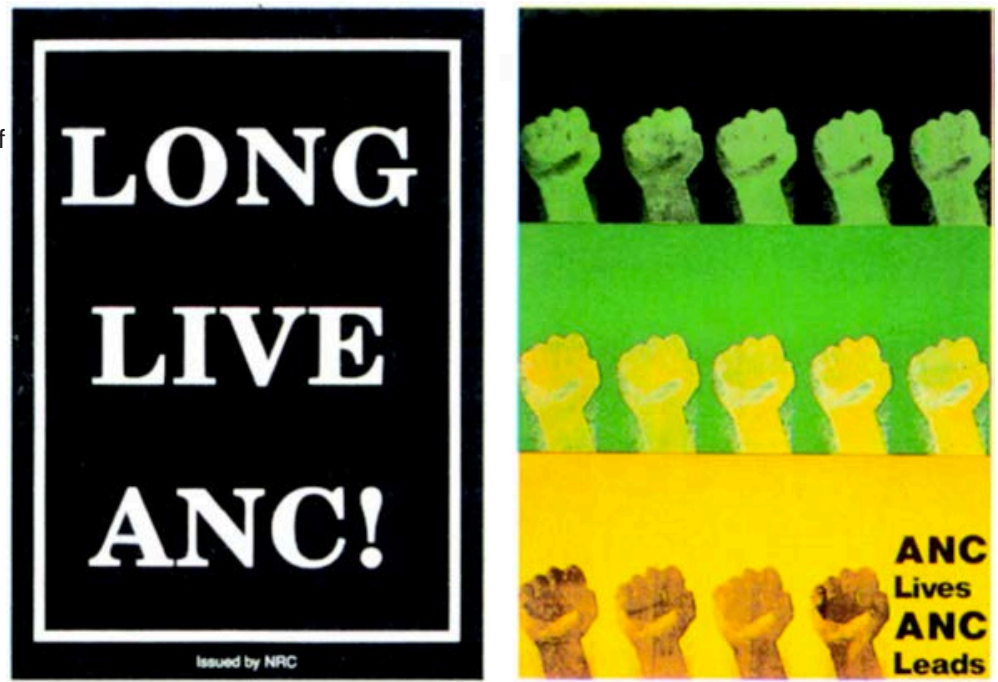


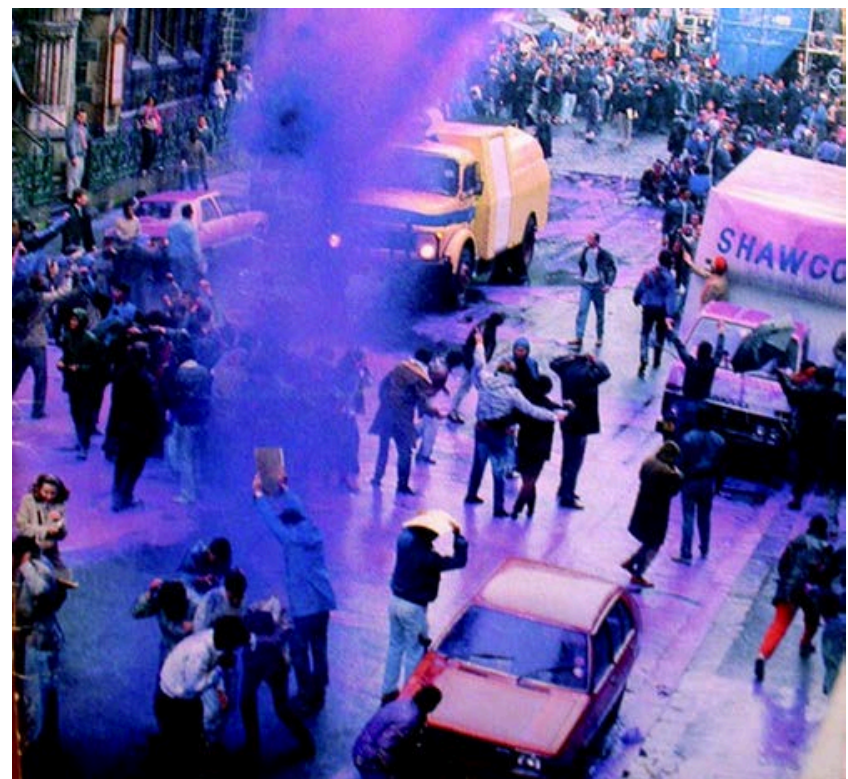

Figure 5 Police firing 'purple rain' on protesters, Cape Town 1989 (photographer unknown, from the cover of Die Suid Afrikaan, 1989, Tafelberg Publishers). 